\title{
Ophthalmologic Manifestations of Carotid Occlusive Disease
}

\author{
J. D. DUGAN, Jr. and W. R. GREEN \\ Baltimore, Maryland, USA.
}

\begin{abstract}
Summary
Amaurosis fugax is perhaps the best known ocular symptom of carotid vascular disease. An understanding of the symptoms and an ability to recognise the characteristic changes of hypotensive retinopathy and the ocular ischaemic syndrome should be familiar to ophthalmologists. In patients with known cerebrovascular disease a careful ophthalmologic examination should be performed to evaluate for the presence of ocular involvement related to emboli and hypoperfusion. Once identified a variety of non-invasive and invasive techniques may be employed to determine the degree of stenosis and an individual treatment plan initiated. Early recognition and treatment of patients with carotid occlusive disease may prevent more serious complications.
\end{abstract}

Stenosis and occlusion of the carotid arteries are an important source of morbidity and mortality despite current education about the hazards of cigarette smoking and elevated serum cholesterol levels. Patients with carotid artery disease may be seen by ophthalmologists during routine examination or referred with symptoms related to ocular ischaemia. An understanding of the spectrum of ocular manifestations and an ability to recognise the ocular signs and symptoms related to carotid occlusive disease is therefore important. The manifestations of carotid insufficiency encompass a spectrum including transient episodes of monocular blindness (amaurosis fugax), venous stasis retinopathy, and the ocular ischaemic syndrome with rubeosis irides and the development of neovascular glaucoma.

\section{Amaurosis Fugax \\ Amaurosis fugax or transient blindness occurs}

in $30 \%$ to $40 \%$ of patients with ipsilateral carotid atherosclerotic occlusive disease.$^{1-7}$ At the time of its initial description by Moore in $1922,{ }^{8}$ amaurosis fugax was thought to represent benign angiospasm of the retinal vasculature. It was not until 1952, when Fisher ${ }^{9}$ reported on six patients with transient episodes of monocular blindness who later developed contralateral hemiplegia, that our present understanding of the importance of ipsilateral carotid artery disease began. Today, when a patient describes episodes of monocular visual loss lasting between seconds to several minutes with return of normal vision frequently described as a "curtain being raised', carotid vascular disease leads the differential diagnosis.

If the retina is observed in patients with these symptoms, one may frequently see bright yellow or orange, irregular shaped cholesterol emboli at branch points in the retinal arteries as initially described by Hollen-

From: The Eye Pathology Laboratory and Department of Pathology, the Johns Hopkins Medical Institutions, Baltimore, MD, USA.

Correspondence to: W. Richard Green, MD., Eye Pathology Laboratory, Johns Hopkins Hospital, 600 North Wolfe Street, Baltimore, Maryland 21205, USA. 
horst ${ }^{10}$ and confirmed histologically by David and associates. ${ }^{11}$ The appearance of these emboli is sometimes facilitated by light digital pressure on the eye. Less frequently observed are grayish white platelet-fibrin emboli as described by Fisher ${ }^{12}$ which can be seen passing through the retinal vasculature during episodes of visual loss. These emboli tend to cause transient occlusion and fragment at retinal artery bifurcations. The source of both emboli are most frequently from ulcerative plaques of the ipsilateral carotid artery. Occasionally, larger yellowish white calcific emboli may be found within retina vessels, most frequently at the disc margin, and should suggest aortic valve disease as an aetiology. ${ }^{13,14}$ Another hypothesis, recently suggested as an aetiology in cerțain patients with carotid stenosis implicates increased red cell aggregation, decreased red cell deformity and subsequent increase in viscosity secondary to lowered velocity as a cause in some cases of amaurosis fugax. ${ }^{15}$

An interesting form of amaurosis fugax occurring after exposure to bright light has also been described in patients with carotid insufficiency. In 1979, Furlan et al. ${ }^{16}$ described five such patients with severe extracranial carotid disease. In one of these patients with severe internal carotid occlusion, endarterectomy was followed by subsequent resolution of his symptoms. Brigham et al. ${ }^{17}$ reported on two patients with complete occulsion of the ipsilateral carotid artery whose symptoms of bright light amaurosis fugax were relieved by extensive endarterectomy of the distal common and the external carotid arteries. Jacobs et al. ${ }^{18}$ reported the features of four patients with carotid disease who experienced positive after images after bright light exposure. Donnan et al. ${ }^{19}$ examined four patients with blurring of vision on exposure to bright light using visual evoked potentials and found decrease in the visual evoked response in six of eight symptomatic eyes. All of these authors suggest that the increased metabolic demands of the retina upon exposure to bright light is not provided in these patients with compromised ocular blood flow.

Histopathologic evaluation of an eye of a patient with carotid occlusive disease and a history of numerous episodes of amaurosis fugax in his left eye during the year before his death was unremarkable by routine light microscopy. Trypsin digestion of the retina, however, disclosed numerous capillary microanuerysms, loss of overall cellularity, and particular loss of pericytes in the equator and periphery (Fig. 1).

Other causes of amaurosis fugax include retinal migraine ${ }^{20,21}$ postprandial systemic hypoperfusion, ${ }^{22}$ temporal arteritis, ${ }^{21}$ pseudotumour cerebri, ${ }^{21}$ structural cardiac defects, ${ }^{23}$ ophthalmic artery stenosis, ${ }^{24}$ ocular hypertension, ${ }^{21}$ and hyperviscosity syndromes. ${ }^{25,26}$ Rare cases have also been described as the result of arteriovenous malformations, ${ }^{27,28}$ intraorbital tumours, ${ }^{29}$ Moyamoya disease ${ }^{30}$ and spontaneous anterior chamber haemorrhage. ${ }^{31}$

\section{Venous Stasis Retinopathy}

Although less frequent than acute embolic events, carotid arterial disease may progress to include characteristic posterior retinal changes due to relative hypoperfusion. In 1962, Hedges ${ }^{6}$ described retinal changes which included dilation of the retinal veins with or without a 'sausage shaped' appearance and peripheral haemorrhages in association with carotid occlusive disease. Impressed by the venous tortuosity and dilation with mid peripheral retinal, dot-and-blot haemorrhages, superficial flame-shaped nerve fibre layer haemorrhages and microaneurysms, Kearns and Hollenhorst, ${ }^{32}$ called the condition venous stasis retinopathy. This retinopathy is not due to outflow obstruction as seen in central retinal vein occlusions (CRVO) but rather is the result of decreased arterial perfusion pressure and is more correctly termed hypotensive retinopathy. Hypotensive retinopathy usually results from prolonged ischaemia and is most frequently related to either total occlusion of the internal carotid or stenosis of greater than $90 \%$ (Fig. 2) ${ }^{33}$ Kearns et al. found this retinopathy in $5 \%$ of their patients with unilateral and $17 \%$ of their patients with bilateral carotid occulsion. ${ }^{32}$

While it is possible that venous stasis retinopathy may be confused with the nonischaemic, incomplete form of central retinal vein occlusion (CRVO) and diabetic retino- 


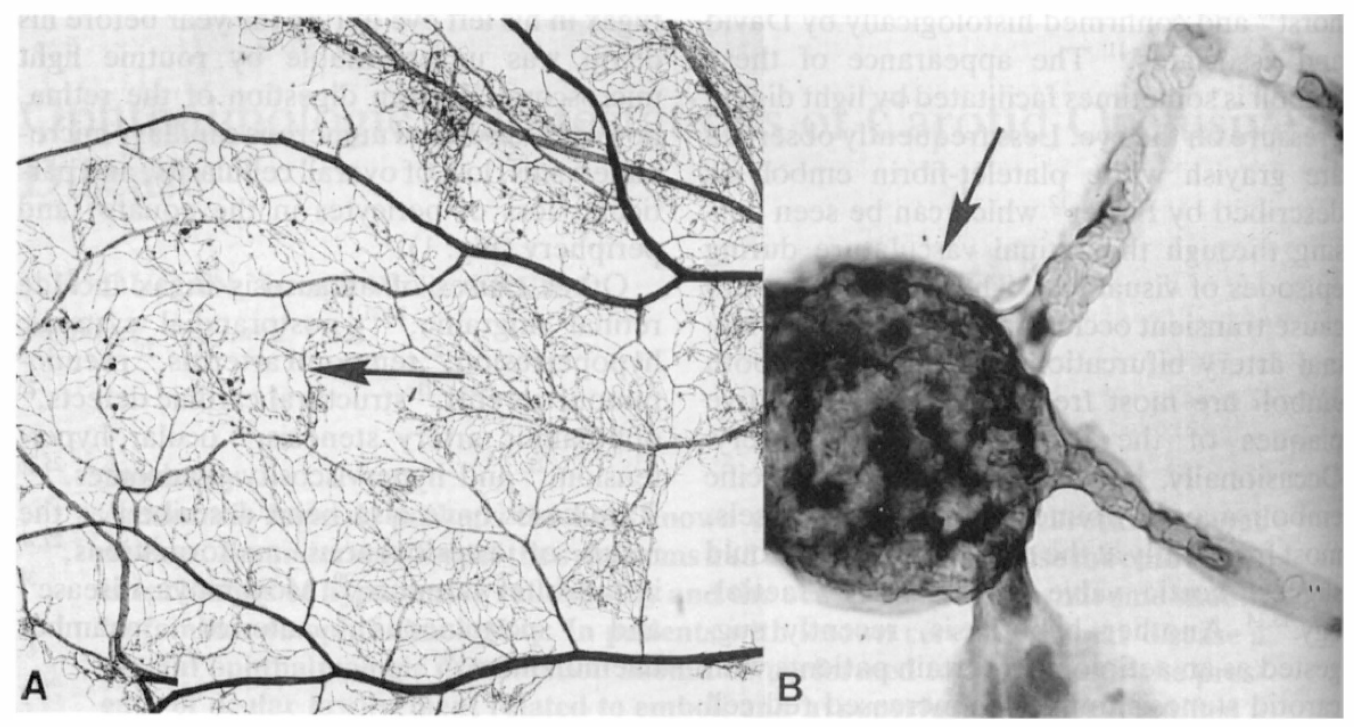

Fig 1 a.

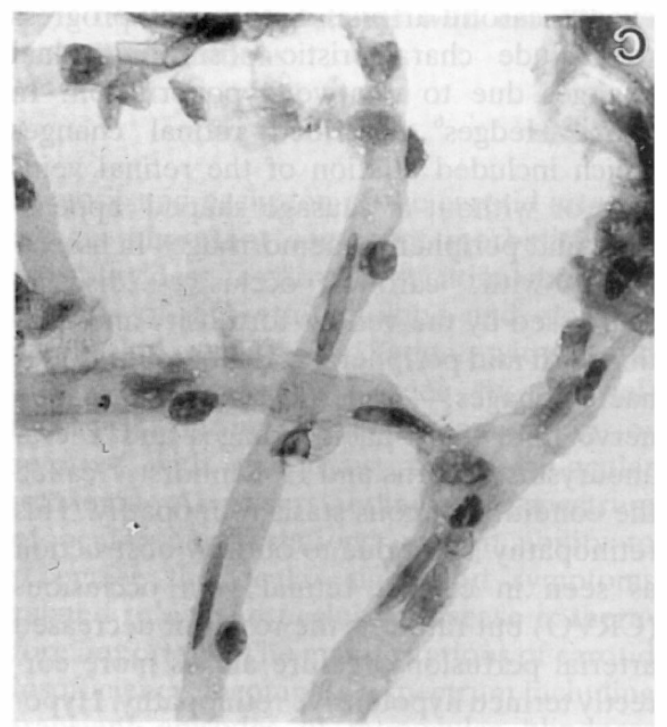

Fig 1c.

Fig. $1 A$, retinal trypsin digest preparation discloses numerous capillary microanuerysms in periphery (arrow).

$B$, Higher power view of peripheral area with microanuerysm (arrow) and overall reduced cellularity.

$C$, Capillaries in posterior pole have a normal one-toone ratio of pericytes and endothelial cells. (Periodic acid-Schiff: $A, \times 12 ; B$ and $C, \times 520)$. (From: Michelson PE, Knox DL, Green WR. Ischaemic ocular inflammation. A Clinicopathologic case report. Arch Opthal 1971, 86: 274-80.
Fig 1 b.

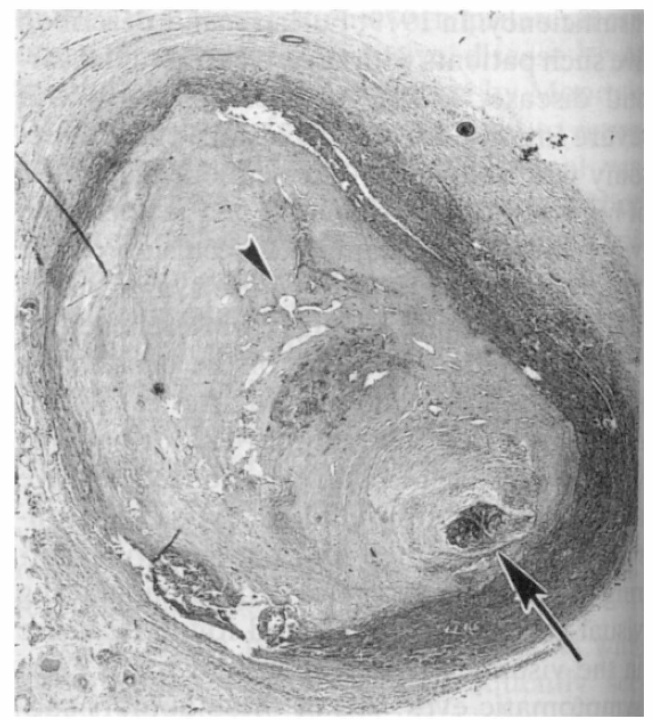

Fig. 2. Portion of the right internal carotid just distal to the bifurcation shows severe atherosclerosis with several small lumens of recanalisation (arrowhead) and one area of recent thrombosis (arrow) (hematoxylineosin, ×12). (From: Kahn M, Green WR, Knox DL, Miller NR: Ocular features of carotid occlusive disease. Retina 1986, 6: 239-52). 


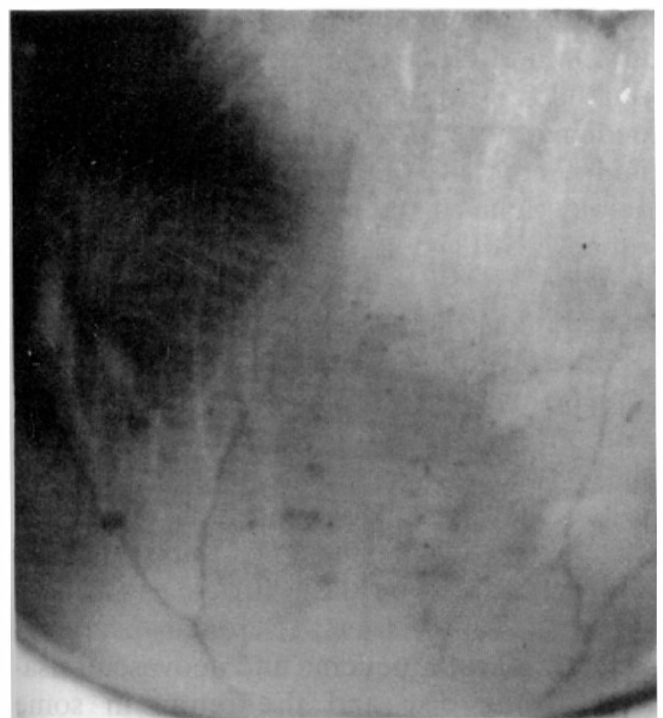

Fig 3a.

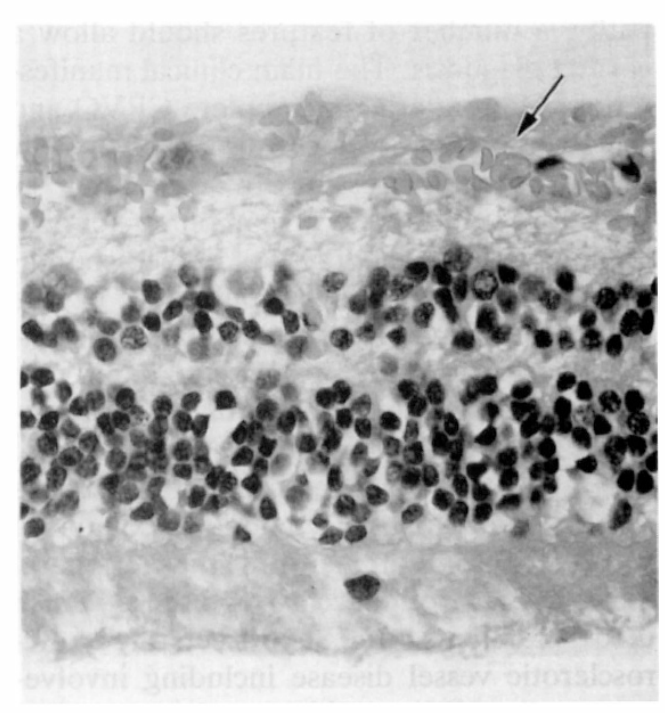

Fig 3b.

Fig. 3. A, Gross internal view of the left eye from a 69-year-old woman with hypotensive retinopathy shows multiple intraretinal haemorrhages and microaneurysms in the equatorial and mid-peripheral areas.

$B$, Superficial mid-peripheral retinal haemorrhage (arrow) (hematoxylin-eosin, $\times 350$ ). (From: Kahn M, Green WR, Knox DL, Miller NR: Ocular features of carotid occlusive disease. Retina 1986, 6: 239-252).

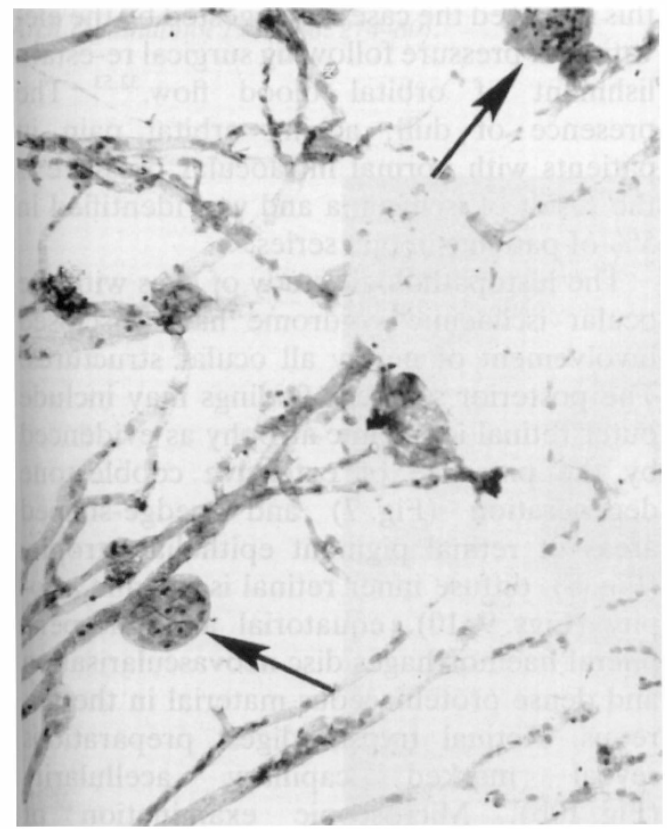

Fig 4a.

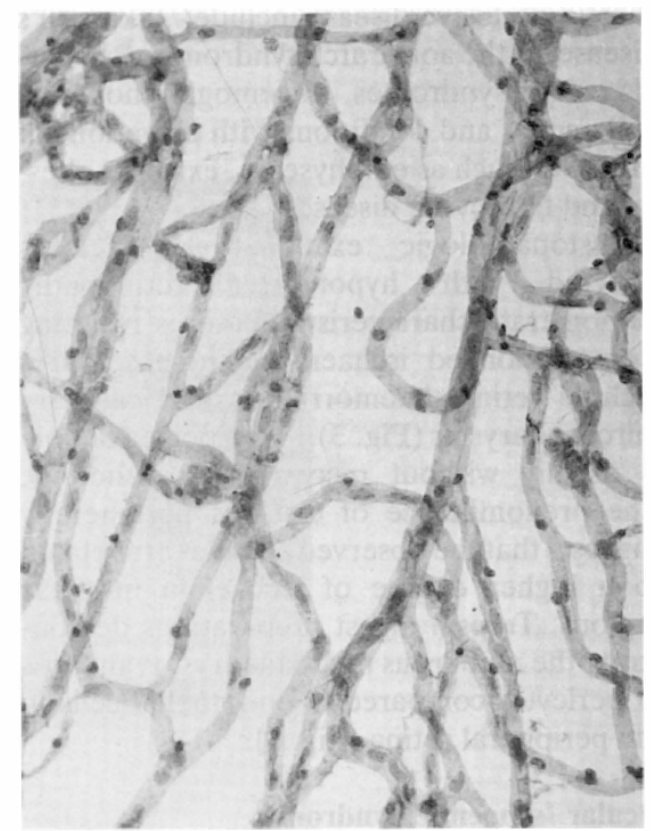

Fig 4 b.

Fig. 4. A, Retinal trypsin digestion preparation of same eye as in Figure 3 reveals numerous capillary microaneurysms in the periphery. Only rare pericytes are present and the endothelial cells appear to have migrated toward and proliferated with microaneurysms (arrows) (periodic acid-Schiff, $\times 100$ ).

$B$, No microaneurysms are present in the posterior pole and there are an equal number of pericytes and endothelial cells (hematoxylin-eosin, periodic acid-Schiff: A, $\times 100 ; B, \times 190)$. (From: Kahn M, Green WR, Knox DL, Miller NR: Ocular features of carotid occlusive disease. Retina 1986, 6: 239-252). 
pathy, a number of features should allow a correct diagnosis. The main clinical manifestation differentiating incomplete CRVO and the retinopathy of carotid disease is the low retinal arterial pressure of the latter as measured by ophthalmodynamometry or oculopneumoplethysmography. ${ }^{34}$ Indeed spontaneous or easily induced pulsation of the retinal artery may be seen. Similarly, the retinal artery pressure is normal in patients with diabetic retinopathy. In addition, diabetic retinopathy is usually bilateral and symmetric with haemorrhages and microaneurysms located throughout the fundus as compared with the predominantly mid-peripheral location in carotid occlusive disease. Since diabetic patients often have accelerated atherosclerotic vessel disease including involvement of the carotid arteries, marked asymmetry between the two eyes should suggest ipsilateral carotid artery disease on the side with greater involvement. ${ }^{35}$

Other conditions which may show similar retinal changes as seen in the retinopathy of carotid occlusive disease include; Takayasu's disease ${ }^{36,37}$ the aortic arch syndromes,${ }^{38}$ hyperviscosity syndromes, haemoglobinopathy, leukaemia, and conditions with elevations of the $\mathrm{PCO}_{2}$ such as emphysema, extreme obesity and fibrocystic disease.

Histopathologic examination of eyes afflicted with hypotensive retinopathy demonstrate characteristic features resulting from prolonged ischaemic. These features include retinal haemorrhages and capillary mircoaneurysms (Fig. 3) ${ }^{39}$ The posterior pole is usually without recognisable pathology. The predominance of changes peripherally suggests that the observed changes are related to a higher degree of ischaemia in these regions. Trypsin digest preparations demonstrate the numerous microaneurysms and loss of pericytes compared to endothelial cells in the peripheral retina (Fig. 4).

\section{Ocular Ischaemic Syndrome}

In certain cases with more severe chronic panocular vascular compromise, the posterior findings may progress to include anterior changes of the ocular ischaemia syndrome as first described by Knox. ${ }^{40}$ Panocular ischaemia may lead to pathologic changes in all ocular structures supplied by the ophthalmic artery. Anterior segment findings include: dilated episcleral veins (Fig. 5a); corneal oedema; anterior chamber cells and flare; a mid-dilated and poorly reactive pupil; cataractous changes and iris atrophy (Fig. 6); and rubeosis iridis with secondary neovascular glaucoma. ${ }^{18,40-46}$ The posterior changes include vascular dilatation and tortuosity, peripheral retinal haemorrhages and microanuerysms (Fig. 5b) and cobblestone degeneration. The retinal changes are similar to those seen in hypotensive retinopathy and represent a progression of this disease to include ischaemic changes in both the inner and outer layers of the retina, narrowing of the retinal arterioles, choroidal perfusion defects, macular oedema and neovascularisation of the disc and the retina in some instances. ${ }^{4,18,47-52}$ Intraocular pressure is usually elevated in those patients with rubeosis irides, but may be normal or decreased, reflecting decreased production of aqueous humour by an ischaemic ciliary body. That this is indeed the case, is suggested by the elevation of pressure following surgical re-establishment of orbital blood flow. ${ }^{32,53}$ The presence of dull, aching orbital pain in patients with normal intraocular pressure is the result of ischaemia and was identified in $5 \%$ of patients in one series. ${ }^{32}$

The histopathologic study of eyes with the ocular ischaemic syndrome have disclosed involvement of nearly all ocular structures. The posterior segment findings may include outer retinal ischaemic atrophy as evidenced by the presence of extensive cobblestone degeneration (Fig. 7) and wedge-shaped areas of retinal pigment epithelial atrophy (Fig. 8), diffuse inner retinal ischaemic atrophy (Figs. 9, 10), equatorial and mid-peripheral haemorrhages disc neovascularisation and dense proteinaceous material in the vitreous. Retinal trypsin digest preparations reveal marked capillary acellularity (Fig. 10b). Microscopic examination of anterior segment discloses dense proteina* ceous material in the anterior and posterior chambers, partial atrophy of the iris (Fig. 11a), iris neovascularisation (Fig. 11b, 12) and peripheral anterior synechiae (Fig. 11b, 12a), partial atrophy of the 


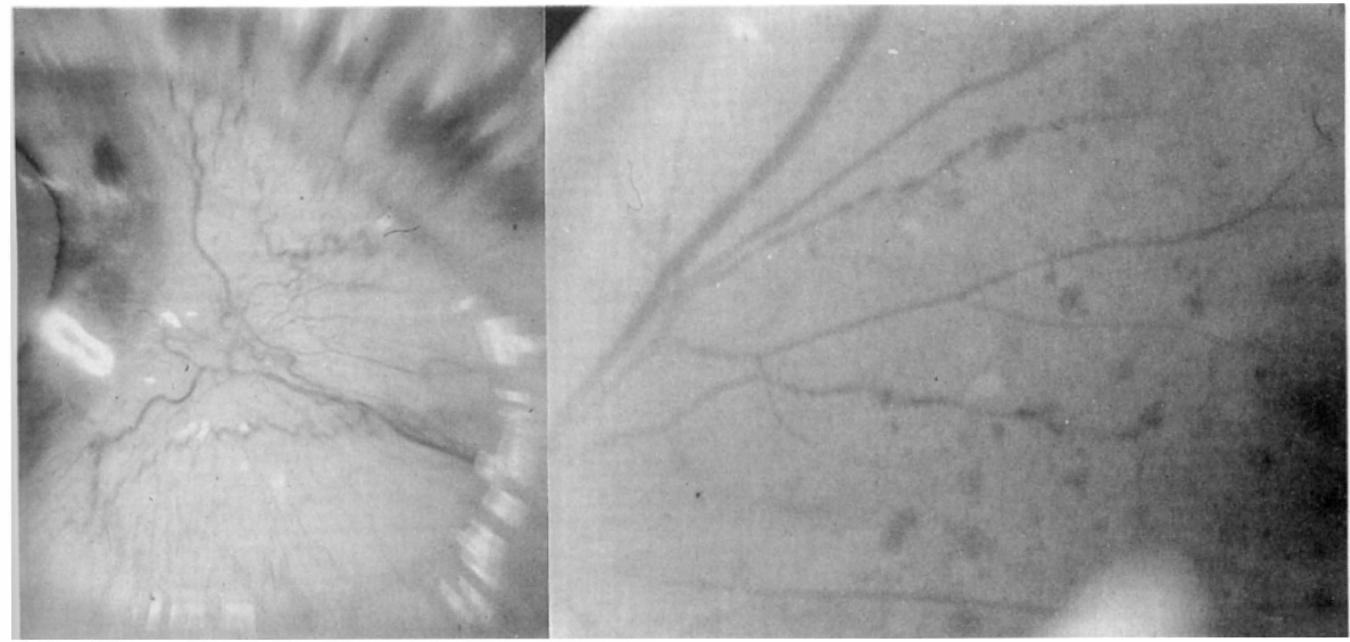

Fig. 5a

Fig. 5b

Fig. 5. A, External appearance with episcleral vascular congestion of the right eye of a 69-year-old man with the ischaemic ocular inflammatory syndrome at initial presentation.

$B$, Ophthalmoloscopic appearance of peripheral retinal haemorrhages, microanuerysms and venous congestion. (From: Michelson PE, Knox DL, Green WR. Ischaemic ocular inflammation. A Clinicopathologic case report. Arch Ophthalmol 1971, 86: 274-80).

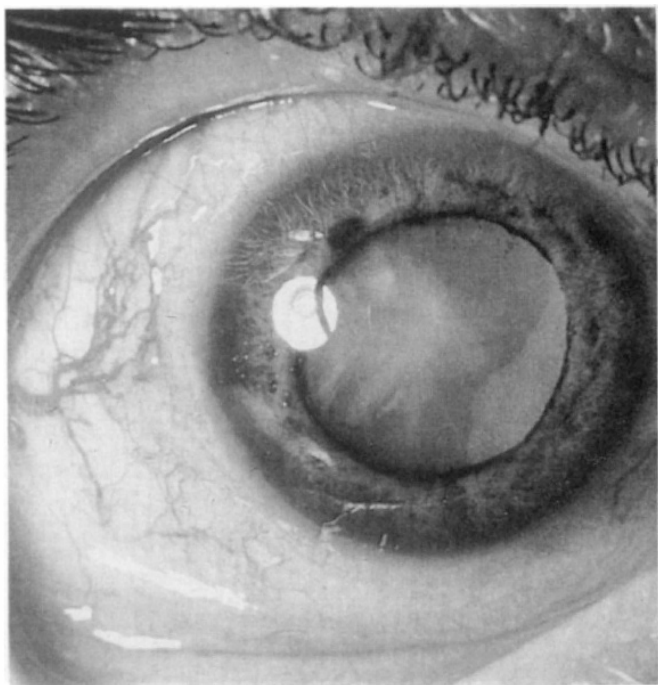

Fig. 6. Appearance four months later of the same patient as illustrated in Figure 5, shows the evolution to a mature cataract, partial iris atrophy and rubeosis irides. (From: Michelson PE, Knox DL, Green WR. Ischaemic ocular inflammation. A Clinicopathologic case report. Arch Opthalmol 1971, 86: 274-80). 


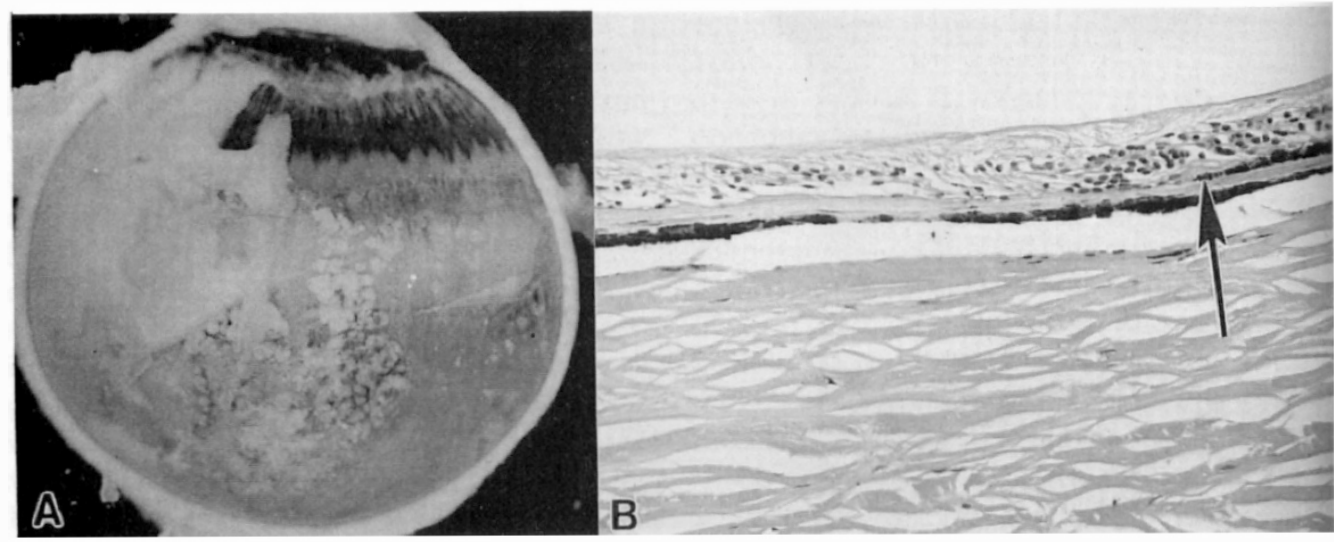

Fig. 7a.

Fig. 7b.

Fig. 7. A, Gross appearance of extensive cobblestone degeneration extending to the mid-periphery in an eye of a 53-year-old man with the ocular ischaemic syndrome.

$B$, Margin of cobblestone lesion (left of arrow) with loss of the retinal pigment epithelium and outer retinal layers up to and including the outer aspect of the inner nuclear layer. (Haematoxylin and eosin $\times 185)$ (From: Michelson PE, Knox DL, Green WR. Ischaemic ocular inflammation. A clinicopathologic case report. Arch Ophthalmol 1971, 86: $274-80$ ).

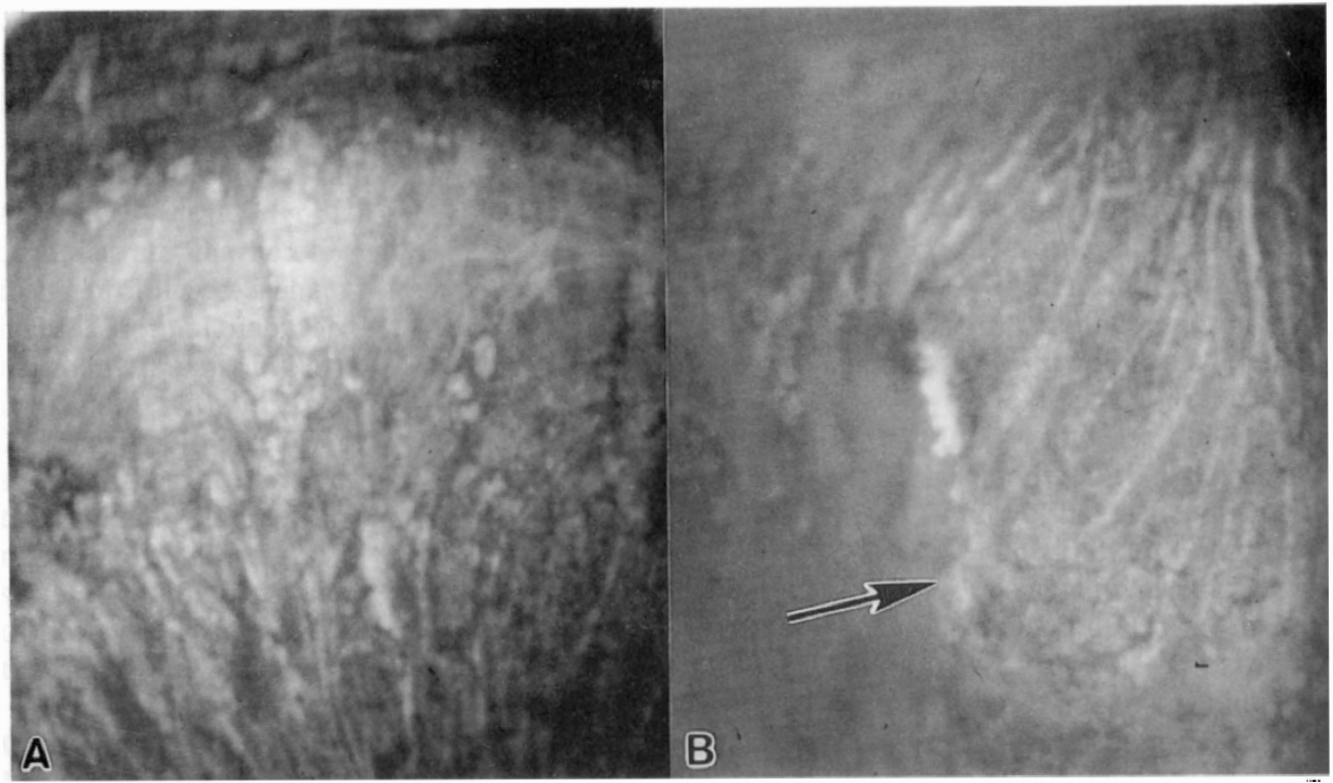

Fig. 8a.

Fig. 8b.

Fig. 8. A, Gross appearance of extensive peripheral outer retinal ischaemic atrophy in eye of a 53-year-old mian with carotid occlusive disease and ocular ischaemic changes.

$B$, In some areas the atrophy has a wedge-shaped configuration. (From: Kahn M, Green WR, Knox DL, Miller NR: Ocular features of carotid occlusive disease. Retina 1986, 6: 239-52). 


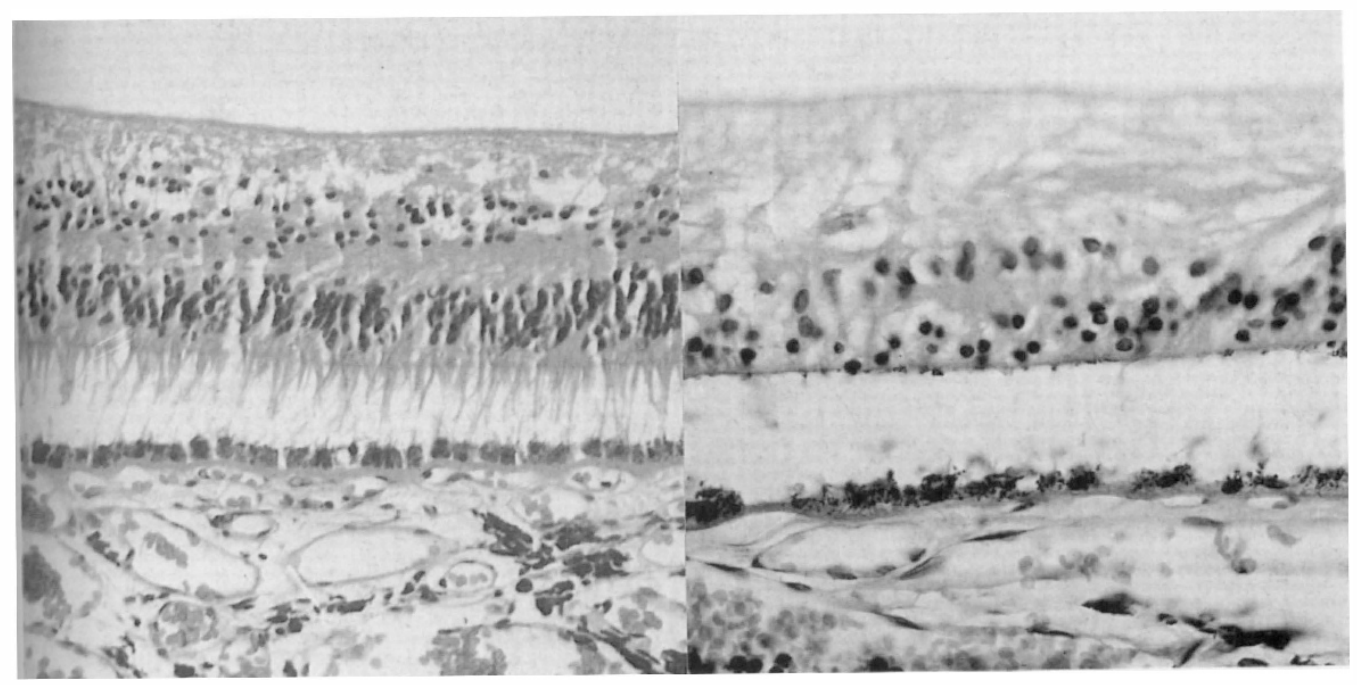

Fig. 9a.

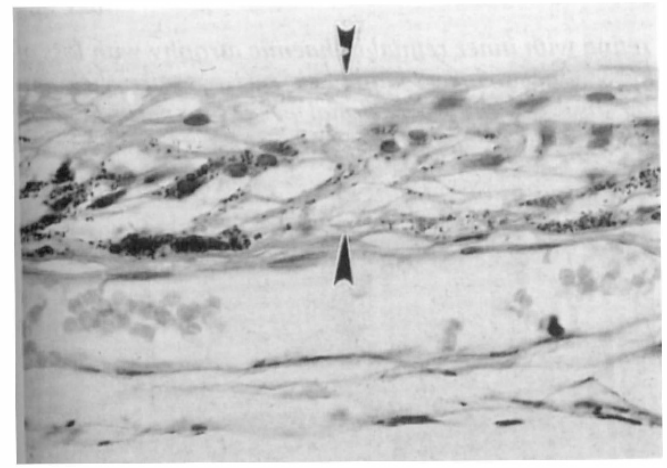

Fig. 9c.

ciliary body (Fig. 12c), and cataractous changes. ${ }^{39,52}$

The progression from hypotensive retinopathy to the ocular ischaemic syndrome may, in part, be mediated by the release of angiogenic factors from ischaemic retina. These factors are thought to be responsible for the neovascularisation of the posterior pole and diffusion of these substances to the anterior segment lead to the development of iris neovascularisation and secondary glaucoma.

\section{Fluorescein Angiography}

Sarkies et al..$^{54}$ using fluorescein angiography to evaluate patients with carotid occlusion or stenosis, found abnormalities in $67 \%$ of cases. The test can be used to demonstrate signifi-
Fig. 9b.

Fig. 9. Microscopic examination from the patient in Figure 8. A, Inner retinal ischaemic atrophy in the macular area (haematoxylin-eosin, $\times 210)$.

$B$, Mid-peripheral area shows inner retinal and partial outer retina ischaemic atrophy (periodic acid-Schiff, $\times 300)$.

$C$, Equatorial retina is reduced to a thin nearly acellular strand (between arrowheads) in an area of inner and outer retinal ischaemic atrophy (periodic acid-Schiff, $\times 300$ ). (From Kahn M, Green WR, Knox DL, Miller NR: Ocular features of carotid occlusive disease. Retina 1986, 6: 239-252).

cant flow obstruction as indicated by delay in appearance of dye in the choroidal and retinal circulation as well as indicating structural abnormalities of the ocular vasculature. When bilateral simultaneous fluorescein angiography is performed, delayed or disparate arm to retina circulation time as well as delayed ciliary circulation at the disc were found to correlate with carotid occlusion. ${ }^{55}$ Fluorescein angiographic features in patients with carotid occlusive disease include: patchy, delayed, irregular choroidal filling; areas of retinal non-perfusion; microaneurysms and venous beading; diffuse late leakage from retinal vessels; leakage at arterial bifurcations suggesting emboli damage; and leakage from

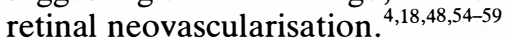




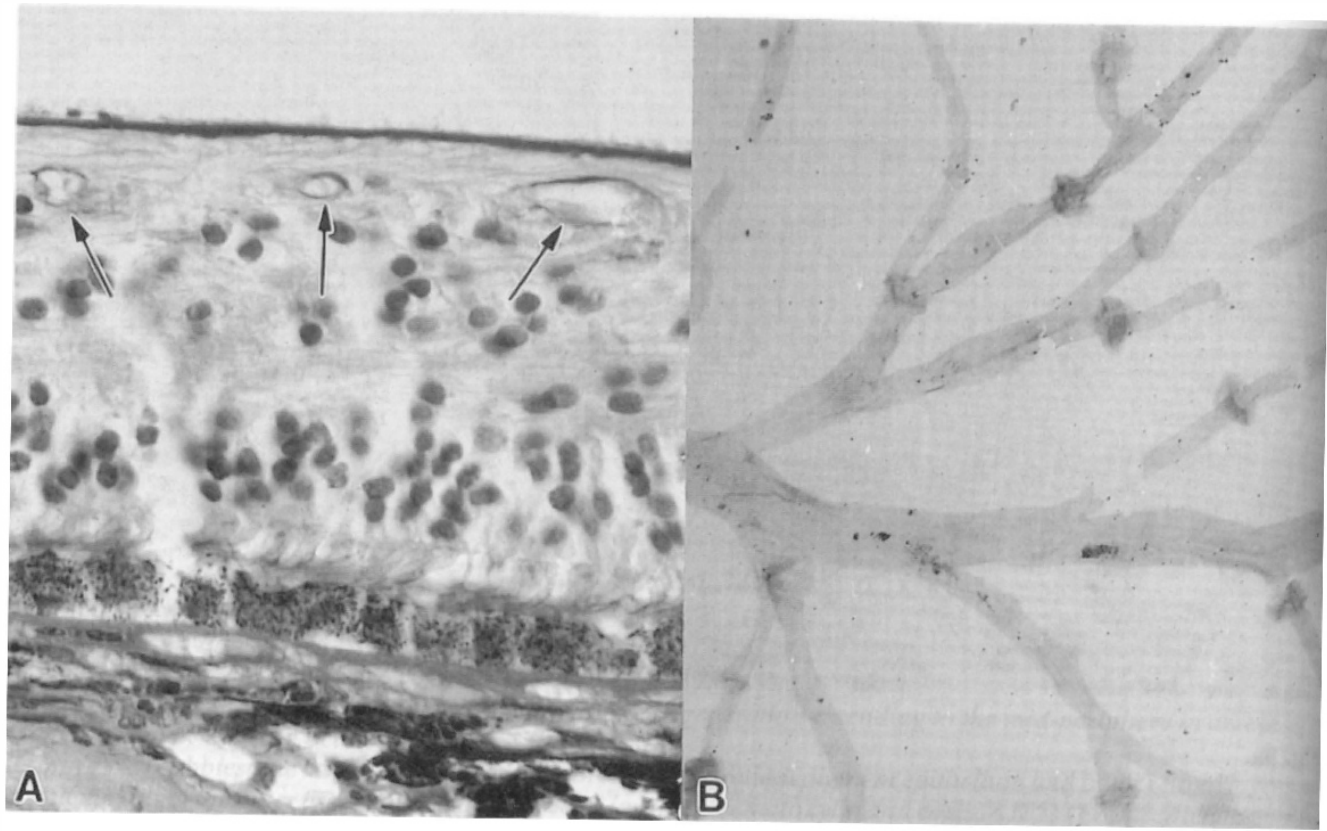

Fig. 10. Ocular ischaemic syndrome. A, Mid-peripheral retina with inner retinal ischaemic atrophy with loss of the inner retinal layers down to the inner portion of the inner nuclear layer. Capillaris (arrows) are acellular. (Periodic acid-Schiff, $\times 525)$. B, Trypsin digest preparation discloses only occasional pericytes (periodic acidSchiff, $\times 160)$. (From Kahn M, Green WR, Knox DL, Miller NR: Ocular features of carotid occlusive disease. Retina 1986, 6: 239-52).
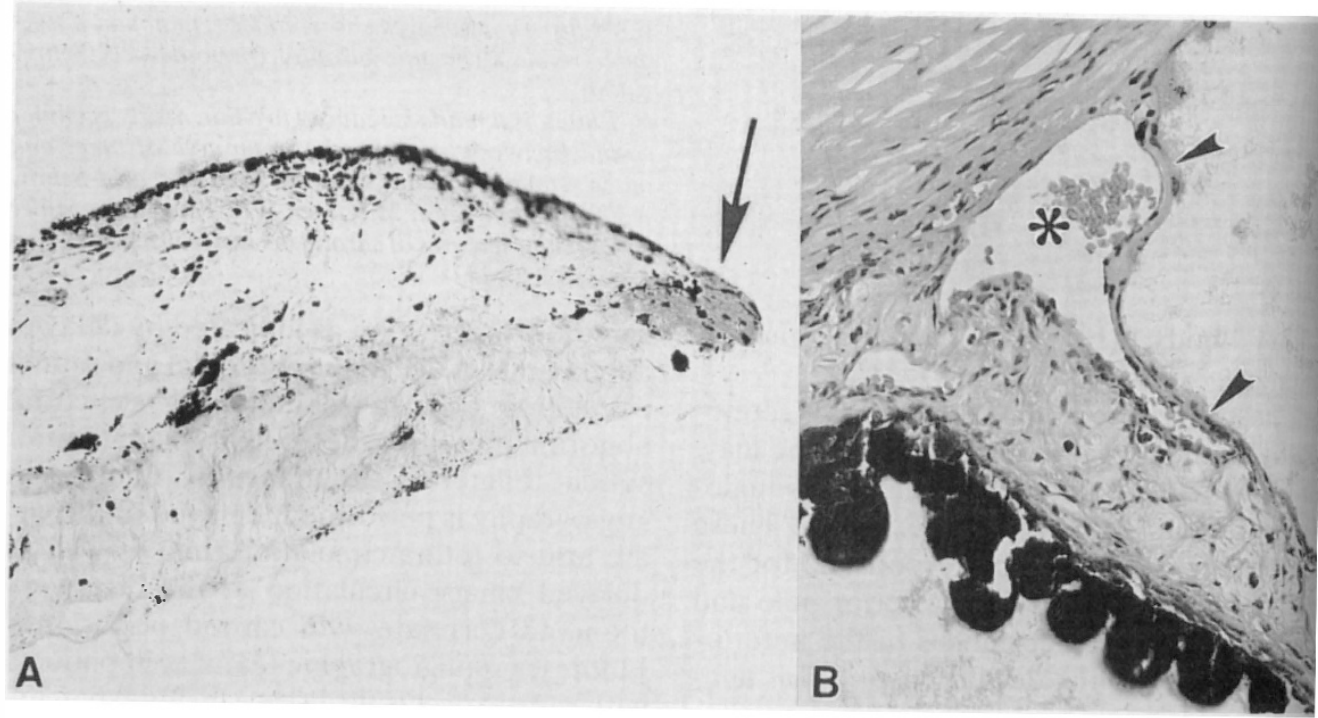

Fig. 11. Anterior segment changes in the ocular ischaemic syndrome. A, Pupillary portion of iris disclosed partial ischaemic necrosis with loss of the pigment epithelium and dilator muscle and partial acellularity of the stroma. Only a small portion of the sphincter muscle (arrow) remains.

$B$, The angle is closed by peripheral anterior synechia and new blood vessels (asterisk) are present on the anterior surface of the iris. Endothelium (arrowheads) with basement membrane extends across the false angle and onto the anterior surface of the iris. (Haematoxylin and eosin: $A$ and $B, \times 170)$. (From: Michelson PE, Knox DL, Green WR: Ischaemic ocular inflammation. A Clinicopathogic case report. Arch Ophthalmol 1971,86: 274-80). 


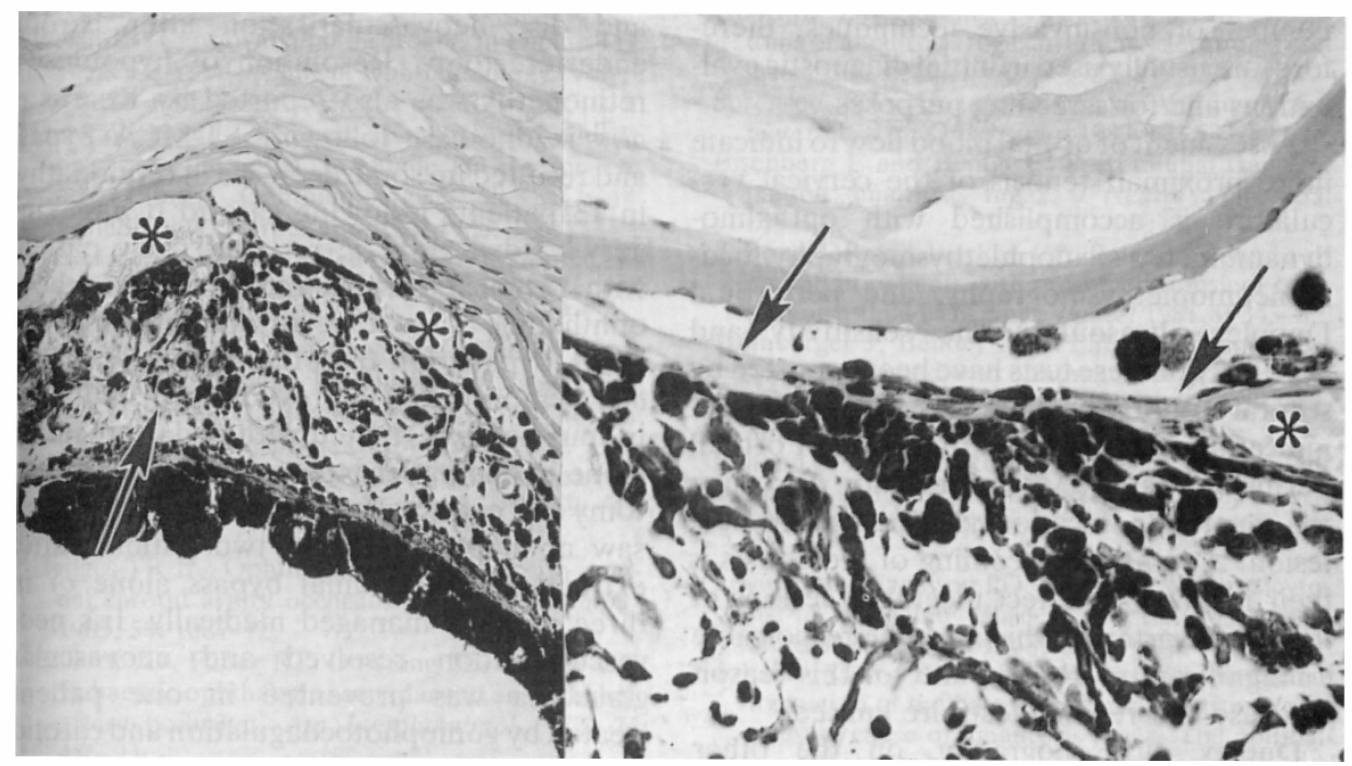

Fig. 12a.

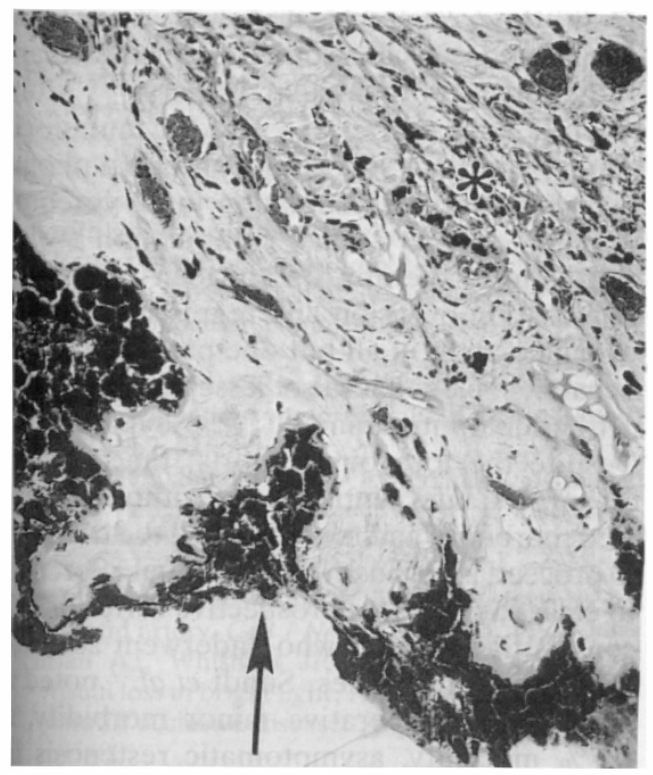

\section{Diagnostic Evaluation}

Evaluation of patients with suspected occlusion or stenosis of the carotid arteries includes a variety of invasive and non-invasive tests. The 'gold standard' for evaluation of the carotid arteries has historically been selective intra-arterial carotid angiography. More
Fig. 12b.

Fig. 12. A, Area shows temporal peripheral anterior synechia with new vessels (asterisk) on the anterior surface of the iris and partial iris atrophy with dispersion of free pigment and pigmented macrophages (arrow) (periodic acid-Schiff, $\times 180)$.

$B$, Nasal iris leaflet shows peripheral anterior synechia with endothelialisation and descemetisation of the false angle and anterior surface of the iris (arrows), rubeosis iridis (asterisk), and pigmented macrophages in the anterior chamber (periodic acid-Schiff, $\times 300$ ).

$C$, Microscopic view reveals partial atrophy of the ciliary body with loss of the non-pigmented epithelium (arrow) and rounding up of pigment (asterisk) (hematoxylin-eosin, ×120). (From: Kahn M, Green WR, Knox DL, Miller NR: Ocular features of carotid occlusive disease. Retina 1986, 6: 239-52).

recently, intra-arterial digital subtraction angiography has replaced conventional angiography in the assessment of patients in many institutions. While angiography is usually performed in most patients preparing for surgical intervention, it is associated with a small but definite morbidity and mortality. ${ }^{60} \mathrm{~A}$ 
number of non-invasive techniques, therefore, are usually used in initial diagnostic evaluations and for screening purposes.

Assessment of orbital blood flow to indicate more proximal stenosis of the cervical vasculature is accomplished with opthalmodynamometry, oculophlethysmography, oculopneumoplethysmography, and periorbital Doppler ultrasound. The sensitivity and specificity of these tests have been reported by several authors. ${ }^{61-65}$ These tests are capable of indicating stenosis and a reduction of orbital perfusion, but give no information regarding the anatomic location of the responsible lesion. Another shortcoming of these tests is their inability to detect ulcerative lesions of the carotid arteries which may be responsible for significant morbidity, and for this reason their use as screening tests are limited.

Duplex ultrasonography, on the other hand, provides both an anatomical picture of the carotid arteries and a pulse Doppler signal at selected points within the displayed segment. This allows visualisation of possible ulcerative plaques as well as an indication of the haemodynamic consequences of a stenotic region based on quantification of peak systolic and end diastolic velocity. Duplex sonography is therefore an excellent screening and diagnostic tool and has been advocated as a highly accurate technique in evaluation of patients with carotid occlusive disease..$^{6,67}$

\section{Treatment}

The indications for surgical intervention for carotid occlusive disease is a matter of debate at present, but it is clearly a multifactorial decision based on the patients operative risk and symptomatology. Ophthalmological intervention, in the form of panretinal photocoagulation, has been reported to result in regression of iris neovascularisation and, when performed prior to closure of the angle, may help prevent the development of neovascular glaucoma. ${ }^{57,68,69}$ In those patients with ocular manifestations of carotid occlusive disease who have undergone carotid endarterectomy or superficial temporal artery to middle cerebral artery (ST-MCA) bypass, improvement of their ophthalmic disease has been reported..$^{32,70-72}$ Neupert et al. ${ }^{70}$ demonstrated resolution of hypotensive retinopathy and disc neovascularisation after carotid endarterectomy. Resolution of hypotensive retinopathy was also reported by Kearns et $a l .{ }^{71}$ in one case following ST-MCA bypass and resulted in 'some decrease in retinopathy' in 13 patients following carotid bypass surgery. ${ }^{32}$ Edwards et al. reported ${ }^{72}$ one patient with the ocular ischaemic syndrome whose ophthalmic disease reversed following STMCA bypass. On the other hand, Sarkies et al. ${ }^{56}$ demonstrated improved microcirculation in four patients treated with endarterectomy alone in one patient treated with endarterectomy and extracranial-intracranial bypass but saw no improvement in two patients after extracranial-intracranial bypass alone or in three patients managed medically. Iris neovascularisation resolved and neovascular glaucoma was prevented in one patient treated by goniophotocoagulation and carotid endarterectomy. ${ }^{73}$ Indeed regression of neovascular glaucoma has been observed following intracranial-extracranial bypass ${ }^{74}$ as well as in three cases treated with peripheral cryoablation, cyclocryotherapy of the ciliary body and cerebrovascular surgery. ${ }^{58,75}$ More recently Johnston et al. ${ }^{57}$ used a multidisciplinary approach involving panretinal photocoagulation or cryoablation and cerebrovascular surgery in combination with anti-platelet therapy on thirteen eyes with stabilisation of vision and regression of neovascularisation in all but one patient. Ocular ischaemic pain has also lessened following extracranial-intracranial bypass. ${ }^{32,69,76}$

Despite the foregoing reports, the decision for surgical intervention is not without associated morbidity and mortality and the decision to proceed is based on an individual approach to each patient. In a prospective series of 252 consecutive patients who underwent 282 carotid endarterectomies, Sundt et al. ${ }^{77}$ noted a one per cent operative minor morbidity, a $0.7 \%$ mortality, asymptomatic restenosis in $10 \%$ and severe stenosis or occlusion in $3 \%$. Actuarial analysis indicated that the cumulative probability of ipsilateral stroke, transient ischaemic attack, or reversible ischaemic neurologic deficit was $4 \%$ at one month and $8 \%$ at five years. ${ }^{77}$

Key words: Amaurosis fugax, Atherosclerosis, Carotid occlusive disease, Ocular ischaemic syndrome, Venous stasis retinopathy. 


\section{References}

${ }^{1}$ Walsh JB: Cardiovascular disorders. In Duane TD, Jaeger EA, eds. Clinical Ophthalmology. Vol. 5. Ch. 22. Philadelphia: Harper and Row $1985 ; 3-4$.

${ }^{2}$ Henkind $\mathrm{P}$ and Chambers JK: Arterial occlusive disease of the retina. In Duane TD, Jaeger EA, eds. Clinical Ophthalmology. Vol. 3. Ch. 14. Philadelphia: Harper and Row 1985: 1-6.

${ }^{3}$ Wise GN, Dollery CT, Henkind P: The retinal circulation. New York: Harper and Row 1971: 309-11.

${ }^{4}$ Sanborn GE and Magargal LE: Carotid artery disease and the eye. In Duane TD, Jaeger EA, eds. Clinical Ophthalmology. Vol. 3. Ch. 14a. Philadelphia: Harper and Row 1985: 1-12.

${ }^{5}$ Gordon N: Ocular manifestations of internal carotid artery occlusion. $\mathrm{Br} J$ Ophthalmol 1959, 43: 257-67.

${ }^{6}$ Hedges TR Jr.: Ophthalmoscopic findings in internal carotid artery occlusion. Am J Ophthalmol 1963, 55: 1007-12.

${ }^{7}$ Bullock JD, Falter RT, Downing JE, Snyder HE: Ischaemic ophthalmia secondary to an opthalmic artery occlusion. Am J Ophthalmol 1972; 74: 486-93.

${ }^{8}$ Moore RF: Medical Ophthalmology. Philadelphia: P. Blakiston, Son and Co., 1922: 63-65.

${ }^{9}$ Fischer M: Transient monocular blindness associated with hemiplegia. Arch Ophthalmol 1952, 47: 167-203.

${ }^{10}$ Hollenhorst RW: Ocular manifestations of insufficiency or thrombosis of the internal carotid artery. Am J Ophthalmol 1959, 47: 753-67.

${ }^{11}$ David NJ, Klintworth GK, Friedberg SJ, Dillon M: Fatal atheromatous cerebral embolism associated with bright plaques in the retinal arterioles. Report of a case. Neurology 1963, 13: 708-13.

${ }^{12}$ Fisher CM: Observation of the fundus oculi in transient monocular blindness. Neurology 1959, 9: 333-47.

${ }^{13}$ Penner R and Font RL: Retinal embolism from calcified vegetations of aortic valve. Arch Ophthalmol 1969, 81: 565-8.

${ }^{1 / 4}$ Arruga J and Sanders MD: Ophthalmologic findings in 70 patients with evidence of retinal embolism. Ophthalmology 1982, 89; 1336-47.

${ }^{15}$ Ross RT and Morrow IM: Ocular and cerebral ischaemic mechanisms in disease of the internal carotid artery. Can J Neurol Sci 1984, 11: 262-8.

${ }^{16}$ Furlan AJ, Whisnant JP, Kearns TP: Unilateral visual loss in bright light. An unusual symptom of carotid occlusive disease. Arch Neurol 1979, 36: 675-80.

${ }^{7}$ Brigham RA, Youkey JR, Clagett GP, Walton MA, Lary MA, Fischer DF, Wind G: Bright-light amaurosis fugax: An unusual symptom of retinal hypoperfusion corrected by external carotid revascularisation. Surgery 1985, 97: 363-8.

'Jacobs NA and Ridgway AEA: Syndrome of ischaemic ocular inflammation: Six cases and a review. Br J Ophthalmol 1985, 69: 681-7.

${ }^{9}$ Donnan GA, Sharbrough FW, Whisnant JP: Carotid occlusive disease. Effect of bright light on visual evoked response. Arch Neurol 1982, 39: 687-9.
${ }^{20}$ Goodwin JA, Gorelick PB, Helgason CM: Symptoms of amaurosis fugax in atherosclerotic carotid artery disease. Neurology 1987, 37: 829-32.

${ }^{21}$ Sorensen PN: Amaurosis fugax: An unselected material. Acta Ophthalmol 1983, 61: 583-8.

${ }^{22}$ Eisenberg E and Bental E: Postprandial transient painful amaurosis fugax. J Neurol 1986, 233: 209-11.

${ }^{23}$ deBono DP and Warlow CP: Potential sources of emboli in patients with presumed transient cerebral or retinal ischaemic. Lancet 1981, i: 343-6.

${ }^{24}$ Weinberger J, Bender AN, Yang WC: Amaurosis fugax associated with ophthalmic artery stenosis: Clinical simulation of carotid artery disease. Stroke 1980, 11: 290-3.

${ }^{25}$ Milikan CH, Siekert RG, Whisnant JP: Intermittent carotid and vertebral-basilar insufficiency associated with polycythemia. Neurology 1960, 10: 188-96.

${ }^{26}$ Levine J and Swanson PD: Idiopathic thrombocytosis: A treatable cause of transient ischaemia attacks. Neurology 1968, 18: 711-13.

${ }^{27}$ Fritz W, Klein HJ, Schmidt K: Arteriovenous malformation of the posterior ethmoidal artery as an unusual cause of amaurosis fugax: The ophthalmic steal syndrome. J Clin Neuro-ophthalmol 1989, 9: 165-8.

${ }^{28}$ Bogousslavsky J, Vinuela F, Barnett HJM, Drake CG: Amaurosis fugax as the presenting manifestation of dural arteriovenous malformation. Stroke 1985, 16: 891-3.

${ }^{29}$ Manor RS and Ben Sira I: Amaurosis fugax at downward gaze. Surv Ophthalmol 1987, 31: 411-6.

${ }^{30}$ Noda S, Nayasaka S, Setogawa T, Matsumoto S: Ocular symptoms of Moyamoya disease. Am J Ophthalmol 1987, 103: 812-6.

${ }^{31}$ Kosmorsky GS, Rosenfeld SI, Burde RM: Transient monocular obscuration-? amaurosis fugax: A case report. Br J Ophthalmol 1985, 69: 688-90.

${ }^{32}$ Kearns TP, Siekert RG, Sundt JR TM: The ocular aspects of bypass surgery of the carotid artery. Mayo Clin Proc 1979, 54: 3-11.

${ }^{33}$ Kearns TP: Ophthalmology and the carotid artery. Am J Ophthalmol 1979, 88: 714-22.

${ }^{34}$ Kearns TP: Differential diagnosis of central retinal vein obstruction. Ophthalmology 1983, 90: 475-80.

${ }^{35}$ Kearns TP and Hollenhorst RW: Venous stasis retinopathy of occlusive disease of the carotid artery. Mayo Clin Proc 1963, 38: 304-12.

${ }^{36}$ Ostler HB: Pulseless disease (Takayasu's disease). Am J Ophthalmol 1963, 43: 583-9.

${ }^{37}$ Hirose K: A study of fundus changes in the early stages of Takayasu-Ohnishi (pulseless) disease. Am J Ophthalmol 1963, 55: 295-301.

${ }^{38}$ Kahn M, Knox DL, Green WR: Clinicopathologic studies of a case of aortic arch syndrome. Retina 1986, 6: 228-33.

${ }^{39}$ Kahn M, Green WR, Knox DL, Miller NR: Ocular features of carotid occlusive disease. Retina 1986 , 6:1 239-52.

${ }^{40}$ Knox DL: Ischaemic ocular inflammation. Am J Ophthalmol 1965, 60: 995-1002.

${ }^{41}$ Pavlou AT and Wolff HG: The bulbar conjunctival vessels in occlusion of the internal carotid artery. Arch Intern Med 1959, 104: 53-60. 
${ }^{42}$ Knox DL: Ocular aspects of cervical vascular disease. Surv Ophthalmol 1969, 13: 245-62.

${ }^{43}$ Smith JL: Unilateral glaucoma in carotid occlusive disease. J Am Med Assoc 1962, 182: 188-94.

${ }^{44}$ Hoefnagels KLJ: Rubeosis of the iris associated with occlusion of the carotid artery. Ophthalmologica 1964, 148: 196-200.

${ }^{45}$ Mills RP: Anterior segment ischaemia secondary to carotid occlusive disease. J Clin Neuro-Opthalmol 1989, 9: 200-4.

${ }^{46}$ Cowan JR CL, Butler G: Ischaemic oculopathy. Ann Ophthalmol 1983, 15: 1052-7.

${ }^{47}$ Green WR: Retina. In: Spencer WH ed. Ophthalmic Pathology, An Atlas and Textbook. Vol. 2. Philadelphia: W. B. Saunders Co. 1985: 1046-47.

${ }^{48}$ Sturrock GD and Mueller HR: Chronic ocular ischaemia. Br J Ophthalmol 1984, 68: 716-23.

${ }^{49}$ Carter JE: Chronic ocular ischaemic and carotid vascular disease. Stroke 1985, 16: 721-8.

${ }^{50}$ Ros MA, Magargal LE, Hedges Jr TR, Simeone FA: Ocular ischaemia syndrome: Long-term ocular complications. Ann Ophthalmol 1987, 19: 270-2.

${ }^{51}$ Brown GC: Macular edema in association with severe carotid artery obstruction. Am J Ophthalmol 1986, 102: 442-8.

${ }^{52}$ Michelson PE, Knox DL, Green WR: Ischaemic ocular inflammation. A clinicopathologic case report. Arch Ophthalmol 1971, 86: 274-80.

${ }^{53}$ Young LH and Appen RE: Ischaemic oculopathy. A manifestation of carotid artery disease. Arch Neurol 1981, 38: 358-61.

${ }^{54}$ Sarkies NJC, Shilling JS, Ross Russell RW: Fluorescein angiography in carotid disease. Trans Ophthalmol Soc UK 1986, 105: 489-93.

${ }^{55}$ Choromokos EA, Raymond LA, Sacks JG: Recognition of carotid stenosis with bilateral simultaneous retinal fluorescein angiography. Ophthalmol 1982, 89: 1146-8.

${ }^{56}$ Sarkies NJC, Shilling JS, Burnard KG, Browse NL, Ross Russell RW: Assessment by fluorescein angiography of surgical treatment of occlusive carotid artery disease. Stroke 1987, 18: 585-90.

${ }^{57}$ Johnston ME, Gonder JR, Canny CLB: Successful treatment of the ocular ischaemic syndrome with panretinal photocoagulation and cerebrovascular surgery. Can J Ophthalmol 1988, 23: 114-9.

${ }^{58}$ Kiser WD, Gonder J, Magargal LE, Sanborn GE, Simeone F: Recovery of vision following treatment of the ocular ischaemic syndrome. Ann Ophthalmol 1983, 15: 305-10.

${ }^{59}$ Wagner WH, Weaver FA, Brinkley JR, Borchert M, Lindsay SF: Chronic ocular ischaemia and neovascular glaucoma: A result of extracranial carotid artery disease. J Vasc Surg 1988, 8: 551-7.

${ }^{60}$ Faught E, Trader SD, Hannah GR: Cerebral complications of angiography for transient ischaemia and stroke: Prediction of risk. Neurology 1979 , 29: 4-15.

${ }^{61}$ Gee W: Ocular pneumoplethysmography. Surv Ophthalmol 1985, 29: 276-92.
${ }^{62}$ Sanborn GE, Miller NR, Langham ME, Kumar AJ: An evaluation of the currently available noninvasive tests of carotid artery disease. Ophthalmol 1980, 87: 435-9.

${ }^{63}$ Wasserman DH, Hobson RW, Lynch TG, Berry SM; Jamil Z: Ultrasonic imaging and oculoplethysmography in diagnosis of carotid occlusive disease. Arch Surg 1983, 118: 1161-3.

${ }^{6+}$ Wiebers DO, Folger WN, Forbes GS, Younge BR, O'Fallon WM: Ophthalmodynamometry and ocular pneumoplethysmography for detection of carotid occlusive disease. Arch Neurol 1982, 39: 690-1.

${ }^{65}$ Schwartz JA, Flanigan DP, Schuler JJ, Ryan TJ, Castronuovo $\mathrm{JJ}$ : Indirect assessment of carotid occlusive disease by ocular pneumoplethysmography. Stroke 1984, 15: 521-6.

${ }^{66}$ Walsh J, Markowitz I, Kerstein MD: Carotid endarterectomy for amaurosis fugax without angiography. Am J Surg 1986, 152: 172-4.

${ }^{67}$ Lo LY, Ford CS, McKinney WM, Toole JF: Asymptomatic bruit, carotid and vertebrobasilar transient ischaemic attacks-A clinical and ultrasonic correlation. Stroke 1986, 17: 65-8.

${ }^{68}$ Carter JE: Panretinal photocoagulation for progressive ocular neovascularisation secondary to occlusion of the common carotid artery. Ann Ophthalmol 1984, 16: 572-6.

${ }^{69}$ Eggleston TF, Bohling CA, Eggleston HC, Hershey FB: Photocoagulation for ocular ischaemia associated with carotid artery occlusion. Ann Ophthalmol 1980, 12: 84-7.

${ }^{70}$ Neupert JR, Brubaker RF, Kearns TP, Sundt TM: Rapid resolution of venous stasis retinopathy after carotid endarterectomy. Am J Ophthalmol 1976, 81: 600-2.

${ }^{71}$ Kearns TP, Younge BR, Piepgra DG: Resolution of venous stasis retinopathy after carotid bypass surgery. Mayo Clin Proc 1980, 55: 342-6.

${ }^{72}$ Edwards MS, Chater NL, Stanley JA: Reversal of chronic ocular ischaemia by extracranial-intracranial arterial by-pass: Case report. Neurosurgery 1980, 7: 480-3.

${ }^{73}$ Hauch TL, Busuttil RW, Yoshizumi MO: A report of iris neovascularisation: An indication for carotid endarterectomy. Surgery 1984, 95: 358-62.

${ }^{74}$ Kearns TP and Siebert RG: The ocular aspects of carotid artery surgery. Trans Am Ophthalmol Soc 1978, 76: 247-65.

${ }^{75}$ Coppeto JR, Wand M, Bear L, Sciarra R: Neovascular glaucoma and carotid artery obstructive disease. Am J Ophthalmol 1985, 99: 567-70.

${ }^{76}$ Ausman JI, Lindsay W, Ramsay RC, Chou SN: Ipsilateral subclavian to external carotid and STAMCA bypass for retinal ischaemia. Surg Neurol 1978, 9: 5-8.

${ }^{77}$ Sundt Jr TM, Whisnant JP, Houser OW, Fode NC: Prospective study of the effectiveness and durability of carotid endarterectomy. Mayo Clinic Proc 1990, 65: 625-35. 